\title{
Synthesis and Characterization of Fluorenediylvinylene and Thiophenediylvinylene-Containing Terphenylene-Based Copolymers
}

\section{Min Zheng, Liming Ding, Zhiqun Lin, and Frank E. Karasz*}

Department of Polymer Science \& Engineering, University of Massachusetts, Amherst, Massachusetts 01003

Received April 3, 2002; Revised Manuscript Received October 1, 2002

\begin{abstract}
Two alternating copolymers composed of a terphenylene unit and either a fluorenediylvinylene or a thiophenediylvinylene unit were synthesized by using a Wittig reaction. The products were poly[2',5'-dihexyloxy-p-terphenyl-4,4"-ylenevinylene-alt-2,7-(9,9'-di-n-hexylfluorene)diylvinylene] (A) and poly[2',5'-dihexyloxy-p-terphenyl-4,4"-ylenevinylene-alt-(2,5-thiophenediylvinylene)] (B), respectively. The polymers were characterized by ${ }^{1} \mathrm{H} N \mathrm{NMR},{ }^{13} \mathrm{C} N \mathrm{NR}$, and elemental analysis. The polymers show good solubility in common organic solvents, and the films emit bluegreen and green-yellow light, respectively, on irradiation with UV light. In addition to the fabrication and evaluation of EL devices using both A and $\mathbf{B}$, the photoluminescence of mixtures of $\mathbf{A}$ with an organically modified clay was investigated.
\end{abstract}

\section{Introduction}

Light-emitting diode (LED) technologies that use conjugated polymers have shown substantial promise for electrooptical applications. ${ }^{1-3}$ Important macromolecular structures for light-emitting applications have been recently reviewed. 4,5 In the categories of conjugated polymers, polyfluorene and polythiophene and their derivatives occupy a significant position. Poly(fluorene)s (PFs) are attractive as active components of organic light-emitting diodes because of their thermal and chemical stability and their exceptionally high solution and solid-state fluorescence quantum yields (0.6$0.8){ }^{6-8}$ Moreover, the facile substitution at the 9 -position of the fluorene monomer allows control of polymer properties such as solubility, processability, and morphology. However, for most of the PFs investigated so far, relatively large band gaps and especially a high barrier to hole injection have limited their applications in PLEDs. ${ }^{9,10} \mathrm{~F}$ or polythiophenes, the most attractive characteristics for PLED application are their good stability both in the neutral and in the doped states and their wide el ectronic and optical tunability. ${ }^{11-15}$ In this case application has been limited due to factors such as poor solubility in common organic solvents, as a result of their rigid backbones. ${ }^{16}$ To partially offset these difficulties, it has also been demonstrated that copolymerization of fluorene or thiophene with various aryls permits tunability of electronic properties with enhanced stability. ${ }^{17-19}$

A novel route to improve efficiency and stability of $E L$ devices is to form a composite with an inorganic component with appropriate characteristics to isolate the conjugated polymer chains resulting in the reduction of interchain interaction and the retardation of the penetration of oxygen and moisture into the emissive layer. Such organic-inorganic hybrid composites have demonstrated improved environmental stability, mechanical strength and lower permeability for gases (e.g., $\mathrm{O}_{2}$ ) relative to the corresponding pure polymers. ${ }^{20-22}$

In the present contribution, we report on the syntheses of two new partially conjugated polymers consisting

\footnotetext{
* Corresponding author. E-mail: fekarasz@polysci.umass.edu.
}

of a terphenylene unit linked by either a fluorenediylvinylene or a thiophenediylvinylene moi ety (Scheme 1). The photol uminescence and electrol uminescence of these two polymers were investigated. Composite materials consisting of polymer $\mathbf{A}$ and a modified layered silicate were also prepared, and the optical properties of these composites were studied.

\section{Experimental Section}

General. Commercially available materials were used as received unless noted otherwise. Compounds $\mathbf{1}, \mathbf{2}$, and $\mathbf{9}$ were synthesized according to published procedures. ${ }^{23,24}$ To form the composite, a mica type silicate modified by dimethyl dihydrogenated-tallow ammonium (C15A, Southern Clay Product Inc.) ${ }^{22}$ was intercalated with conjugated polymer $\mathbf{A}$ (Scheme 2). In a typical experiment, a mixture of $\mathbf{A}$ and C15A was dissolved in chloroform ( $20 \mathrm{mg} / \mathrm{mL})$ by stirring overnight at room temperature. The weight ratios of $\mathbf{A}$ to C15A were varied from 10:1 to 1:1. Thus, the concentrations of C15A in the composites studied are $9 \%, 16.7 \%, 33.3 \%$, and $50 \%$. Thin films of the nanocomposite were obtained by spin-coating the solution onto a clean Si substrate at $2500 \mathrm{rpm}$. The average film thickness was about $110 \mathrm{~nm}$.

Melting points were taken on a Fisher-J ohns melting point apparatus and are uncorrected. NMR spectra were collected on a Bruker DPX300 spectrometer in chlor oform-d solvent with tetramethylsilane (TMS) as internal standard. Elemental analysis was carried out in the University of Massachusetts Microanalytical L aboratory. UV-vis spectra were recorded on an IBM 9420 spectrometer. Emission and excitation spectra were obtained on a Perkin-EImer LS 50B spectrometer with a xenon lamp as light source and were corrected in the usual manner. The relative emission quantum yields in chloroform solvent were determined at an excitation wavelength of 360 $\mathrm{nm}$ using the external standard 9,10-diphenylanthracene in cyclohexane $\left(\Phi_{\mathrm{f}}=0.90 \text { when excited at } 360 \mathrm{~nm}\right)^{25,26}$ The excitation wavelength was $360 \mathrm{~nm}$ for both the standard and the polymers, and the refractive indices of chloroform and cyclohexane were taken into account. Differential scanning calorimetry (DSC) was run on a Perkin-EImer DSC-7 using Pyris software; indium and tin were used for calibration. The glass transition temperatures reported were taken as the onset temperatures of the heat capacity discontinuity. The molecular weights of the polymers were determined by gel permeation chromatography with THF as eluent and polystyrene as standard. The small-angle X-ray scattering measurements 
Scheme 1. Synthetic Routes to Polymers

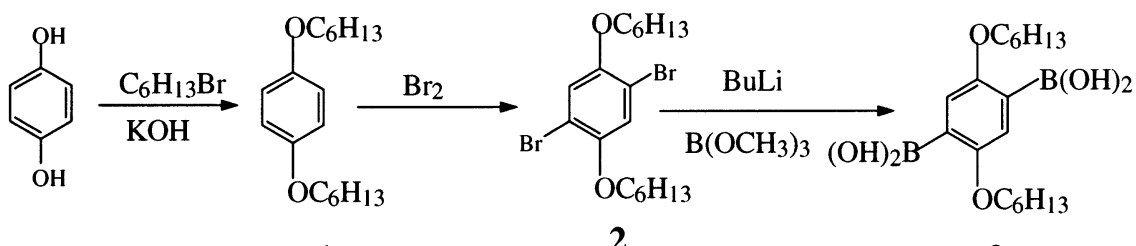

1<smiles>CCOc1cc(P2OCCCO2)c(OCC)cc1B1OCCCO1</smiles>

4

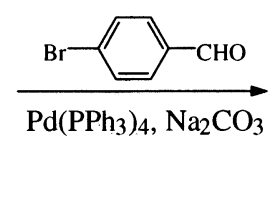

$\mathrm{Pd}\left(\mathrm{PPh}_{3}\right)_{4}, \mathrm{Na}_{2} \mathrm{CO}_{3}$<smiles>CCOc1cc(-c2ccc(C=O)cc2)c(OCC)cc1-c1ccc(C=O)cc1</smiles>

5

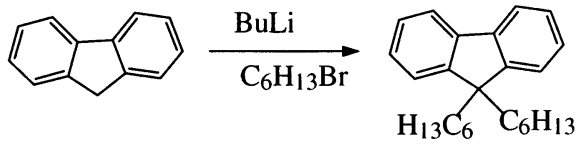

6

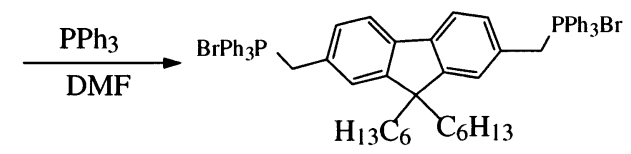

8

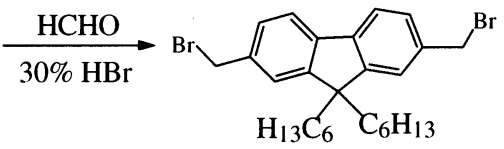

7

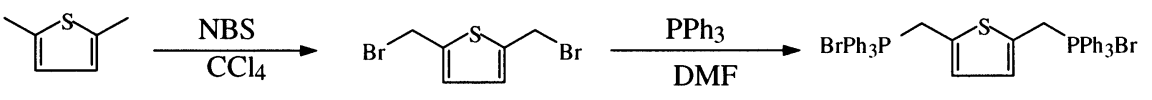

9

10

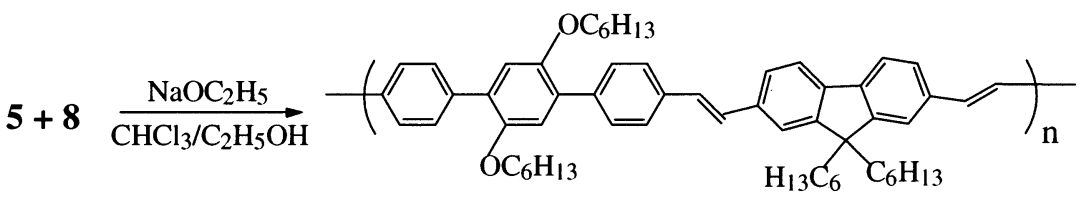

A<smiles>CCOc1cc(-c2ccc(/C=C/c3ccc(/C=C(\C)CC)s3)cc2)c(OCC)cc1-c1ccc(C)cc1</smiles>

B

Scheme 2. Schematic Representation of the Intercalation Process

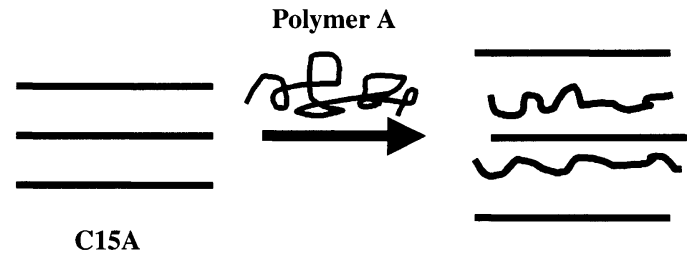

were performed with $\mathrm{Ni}$-filtered $\mathrm{Cu}-\mathrm{K} \alpha$ radiation from a Rigaku Denki Co. rotating anode generator operated at $8 \mathrm{~kW}$. A gas-filled area detector (Siemens Hi-Star) was used to record the scattering pattern. Typical exposure times for the nanocomposites were $\sim 5 \mathrm{~h}$. An Olympus $8 \times 60$ optical microscope in the reflection mode was used to investigate the surface morphology of the nanocomposite. Atomic force microscopy (AFM) studies were performed with a Digital Instrument D3100 scanning force microscope in the tapping mode. Silicon nitride tips on cantilevers (Nanoprobe) with spring constants from 29.3 to $63.9 \mathrm{~N} / \mathrm{m}$ were used.

LED Fabrication and Characterization. Solutions of polymer A and B (20 mg/mL in chloroform) were filtered through $0.2 \mu \mathrm{m}$ Millex-FGS Filters (Millipore Co.) and were then spin-coated on to PEDOT/indium tin oxide (ITO)-coated glass substrates (OFC Co.) under nitrogen. Calcium (400 nm) was evaporated onto the polymer at about $10^{-7}$ Torr, followed by a protective coating of aluminum. The devices were characterized using a system constructed in our laboratory which has been described el sewhere. ${ }^{27}$

Synthesis. 1,4-Bis(hexyloxy-2,5-phenyldiboronic acid) (3). To a solution of $9.75 \mathrm{~g}(22.36 \mathrm{mmol})$ of 1,4-dibromo-2,5bis(hexyloxy)benzene (2) in $100 \mathrm{~mL}$ of absolute diethyl ether under nitrogen at $-78{ }^{\circ} \mathrm{C}, 2.5$ equiv amounts $(23 \mathrm{~mL}, 62.5$ $\mathrm{mmol}$ ) of butyllithium (2.5 $\mathrm{M}$ in hexane) were slowly added. After $2 \mathrm{~h}$ stirring at $-78{ }^{\circ} \mathrm{C}$, the solution was allowed to warm to room temperature and poured into $28 \mathrm{~mL}(230 \mathrm{mmol})$ of trimethoxyborane dissolved in $50 \mathrm{~mL}$ of diethyl ether at -78 
${ }^{\circ} \mathrm{C}$. This mixture was allowed to warm slowly to room temperature and was further stirred for $12 \mathrm{~h}$ when $100 \mathrm{~mL}$ of 2 $\mathrm{M}$ hydrochloric acid was added. After $24 \mathrm{~h}$ of stirring, the precipitate was filtered and washed with $200 \mathrm{~mL}$ of deionized water and ethyl acetate. A white powder $(4.5 \mathrm{~g})$ was obtained after drying in a vacuum at $40{ }^{\circ} \mathrm{C}$ (yield $55 \%$ ); $\mathrm{mp} 150{ }^{\circ} \mathrm{C} .{ }^{1} \mathrm{H}$ NMR (DMSO, $\delta): 7.84(\mathrm{~s}, 4 \mathrm{H}), 7.16(\mathrm{~s}, 2 \mathrm{H}), 3.98(\mathrm{t}, 4 \mathrm{H}), 1.70$ $(\mathrm{m}, 4 \mathrm{H}), 1.38(\mathrm{~m}, 4 \mathrm{H}), 1.28(\mathrm{~m}, 8 \mathrm{H}), 0.90(\mathrm{t}, 6 \mathrm{H}) .{ }^{13} \mathrm{C} N \mathrm{NMR}$ (DMSO, $\delta$ ): $157.22,145.03,118.25,68.69,31.28,29.07,25.47$, 22.38, 14.20.

1,4-Bis(hexyloxy-2,5-phenyldiboronic acid 1,3-propanediol diester) (4). A mixture of 1,4-bis(hexyloxy-2,5phenyldiboronic acid) $(3.65 \mathrm{~g}, 10 \mathrm{mmol})$ and $1.55 \mathrm{~g}(20 \mathrm{mmol})$ of 1,3-propanediol in $100 \mathrm{~mL}$ of toluene was refluxed for $12 \mathrm{~h}$. After cooling to room temperature the solvent was removed. The product was obtained as colorless crystal after recrystallization from hexane (yield 96\%); $\mathrm{mp} 109-110{ }^{\circ} \mathrm{C}$. ${ }^{1 \mathrm{H}} \mathrm{NMR}$ $\left(\mathrm{CDCl}_{3}, \delta\right): 7.10(\mathrm{~s}, 2 \mathrm{H}), 4.15(\mathrm{t}, 8 \mathrm{H}), 3.93(\mathrm{t}, 4 \mathrm{H}), 2.06(\mathrm{~m}$, $4 \mathrm{H}), 1.75(\mathrm{~m}, 4 \mathrm{H}), 1.48(\mathrm{~m}, 4 \mathrm{H}), 1.32(\mathrm{~m}, 8 \mathrm{H}), 0.90(\mathrm{t}, 6 \mathrm{H}) .{ }^{13} \mathrm{C}$ NMR $\left(\mathrm{CDCl}_{3}, \delta\right): 157.77,145.81,120.15,70.14,62.40,32.07$, $29.98,27.70,26.14,23.10,14.46$

2',5'-Dihexyloxy-p-terphenyl-4,4"-dialdehyde (5). 1,4Bis(hexyloxy-2,5-phenyldiboronic acid 1,3-propanediol diester) $(2.97 \mathrm{~g}, 6.7 \mathrm{mmol})$, 4-bromobenzal dehyde $(3 \mathrm{~g}, 16.2 \mathrm{mmol})$, and tetrakis(triphenyl phosphine)palladium $(0.1 \mathrm{~g})$ were mixed in a flask that was deaerated and filled with nitrogen. Toluene ( $100 \mathrm{~mL}$ ) and $2 \mathrm{M}$ sodium carbonate $(50 \mathrm{~mL})$ were added. The mixture was refluxed under nitrogen for $12 \mathrm{~h}$. After cooling, the separated organic layer was dried with $\mathrm{MgSO}_{4}$. Recrystallization from ethanol yielded $2.12 \mathrm{~g}(65 \%)$ of bright yellowgreen crystals; $\mathrm{mp} 78-80^{\circ} \mathrm{C} .{ }^{1} \mathrm{H} N M R\left(\mathrm{CDCl}_{3}, \delta\right): 10.1(\mathrm{~s}, 2 \mathrm{H})$, 7.8-8.0 (dd, 8H), $7.05(\mathrm{~s}, 2 \mathrm{H}), 3.95(\mathrm{t}, 4 \mathrm{H}), 1.75(\mathrm{~m}, 4 \mathrm{H}), 1.30$ $(\mathrm{m}, 12 \mathrm{H}), 0.90(\mathrm{t}, 6 \mathrm{H}) .{ }^{13} \mathrm{C} \mathrm{NMR}\left(\mathrm{CDCl}_{3}, \delta\right): 192.02,150.39$, $144.59,135.04,130.36,130.17,129.42,115.88,69.65,31.40$, 29.23, 25.73, 22.55, 13.96. Elemental calcd for $\mathrm{C}_{32} \mathrm{H}_{38} \mathrm{O}_{4}$ : C, 78.98; H, 7.87. Found: C, 78.03; H, 7.79.

9,9-Di-n-hexylfluorene (6)..$^{28}$ To a solution of $8.3 \mathrm{~g} \mathrm{(50}$ $\mathrm{mmol}$ ) of fluorene in $150 \mathrm{~mL}$ of absolute diethyl ether at -78 ${ }^{\circ} \mathrm{C}, 50 \mathrm{~mL}$ (125 mmol) of butyllithium $(2.5 \mathrm{M}$ solution in hexane) was slowly added under nitrogen. After $2 \mathrm{~h}$ stirring at $-78{ }^{\circ} \mathrm{C}, 18 \mathrm{~mL}(125 \mathrm{mmol})$ of $\mathrm{n}$-hexyl bromide was added dropwise. The solution was warmed to room temperature, stirred overnight, and poured into water. The organic layer was separated and dried over $\mathrm{MgSO}_{4}$, and the solvent was removed. The crude product obtained was purified by recrystallization from hexane (yield 68\%); $\mathrm{mp} 36-39^{\circ} \mathrm{C}$. ${ }^{1} \mathrm{H}$ NMR $\left(\mathrm{CDCl}_{3}, \delta\right): 7.85(\mathrm{~d}, 2 \mathrm{H}), 7.4-7.5(\mathrm{~m}, 6 \mathrm{H}), 2.05-2.15(\mathrm{t}, 4 \mathrm{H})$, $1.2(\mathrm{~m}, 12 \mathrm{H}), 0.9(\mathrm{t}, 6 \mathrm{H}), 0.78(\mathrm{~m}, 4 \mathrm{H}) .{ }^{13} \mathrm{C} \mathrm{NMR}\left(\mathrm{CDCl}_{3}, \delta\right):$ $150.63,141.11,126.95,126.67,122.77,119.61,54.98,40.43$, $31.49,29.73,23.71,22.56,13.98$.

2,7-Bis(bromomethyl)-9,9'-di-n-hexylfluorene (7).29 A

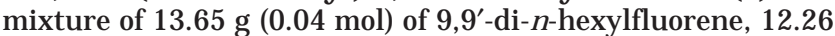
$\mathrm{g}(0.4 \mathrm{~mol})$ of paraformaldehyde, and $123 \mathrm{~g}$ of $30 \% \mathrm{HBr}$ solution in acetic acid was stirred for $24 \mathrm{~h}$ at $60{ }^{\circ} \mathrm{C}$. The reaction mixture was cooled to room temperature and poured into 200 $\mathrm{mL}$ of cold water. The mixture was extracted three times with chloroform, and the extracted solution was washed with water, saturated $\mathrm{NaHCO}_{3}$, and $\mathrm{NaCl}$. The organic solution obtained was then dried with anhydrous $\mathrm{MgSO}_{4}$. A pale yellow liquid was obtained after evaporating the solvent. The liquid was purified by a silica gel column using a mixture of hexane and ethyl acetate (10/1) as an eluent, resulting in $16.6 \mathrm{~g}(80 \%)$ of a col orless liquid. ${ }^{1} \mathrm{H}$ NMR $\left(\mathrm{CDCl}_{3}, \delta\right): 7.25-7.6(\mathrm{~m}, 6 \mathrm{H}), 4.5$ $(\mathrm{s}, 4 \mathrm{H}), 1.85(\mathrm{~m}, 4 \mathrm{H}), 0.85-1.0(\mathrm{~m}, 10 \mathrm{H}), 0.67(\mathrm{t}, 6 \mathrm{H}), 0.55(\mathrm{~m}$, $6 \mathrm{H}) .{ }^{13} \mathrm{C} \mathrm{NMR}\left(\mathrm{CDCl}_{3}, \delta\right): 152.09,141.17,137.33,128.44$, 123.97, 120.49.

2,7-Bis[(p-triphenylphosphonio)methyl]-9,9'-di-nhexylfluorene Dibromide (8). The synthesis was carried out by heating a mixture of triphenyl phosphine $(10 \mathrm{~g}, 40 \mathrm{mmol})$ and 2,7-bis(bromomethyl)-9,9'-di-n-hexylfluorene (6.5 g, 12.5 $\mathrm{mmol})$ in dimethylformamide $(100 \mathrm{~mL})$ at $105-110{ }^{\circ} \mathrm{C}$ under nitrogen overnight. The reactant was cooled to room temperature and added slowly to $300 \mathrm{~mL}$ of ether while stirring. The white solid was filtered, washed with ether, and dried in a vacuum oven at $40{ }^{\circ} \mathrm{C}$. Yield: $12.4 \mathrm{~g}(95 \%) ; \mathrm{mp}>200{ }^{\circ} \mathrm{C}$. ${ }^{1} \mathrm{H}$
NMR $\left(\mathrm{CD}_{3} \mathrm{OD}, \delta\right): 7.6-7.87(\mathrm{~m}, 30 \mathrm{H}), 6.8-7.2(\mathrm{~m}, 6 \mathrm{H}), 5.05-$ $5.10(\mathrm{~d}, 4 \mathrm{H}), 1.6(\mathrm{~m}, 4 \mathrm{H}), 0.8-1.2(\mathrm{~m}, 16 \mathrm{H}), 0.15(\mathrm{br}, 6 \mathrm{H}) .{ }^{31} \mathrm{P}$ NMR $\left(C D_{3} O D, \delta\right): 23.84$.

2,5-Bis[(p-triphenylphosphonio)methyl]thiophene Dibromide (10). The compound was obtained according to the above procedure from triphenyl phosphine $(5 \mathrm{~g}, 20 \mathrm{mmol})$ and 2,5-bis(bromomethyl)thiophene 30 (1.9 g, $7 \mathrm{mmol}$ ). Yield: $7.3 \mathrm{~g}$ (93\%). ${ }^{1} \mathrm{H} N M R\left(\mathrm{CD}_{3} \mathrm{OD}, \delta\right): 7.6-7.9(\mathrm{~m}, 30 \mathrm{H}), 6.75(\mathrm{~s}, 2 \mathrm{H})$, 5.35-5.40 (d, 4H) ${ }^{13} \mathrm{C}$ NMR $\left(\mathrm{CD}_{3} \mathrm{OD}, \delta\right): 137.15,135.76$, $135.69,135.63,132.90,132.08,132.01,131.92,119.88,118.72$. ${ }^{31} \mathrm{P}$ NMR $\left(\mathrm{CD}_{3} \mathrm{OD}, \delta\right): 22.41$.

Poly[2',5'-dihexyloxy-p-terphenyl-4,4'-ylenevinylene2,7-(9,9'-di-n-hexylfluorene)diylvinylene] (A). A solution of sodium $(0.07 \mathrm{~g}, 3 \mathrm{mmol})$ in anhydrous ethanol $(5 \mathrm{~mL})$ was added dropwise at ambient temperature under nitrogen to a mixture of $5(0.49 \mathrm{~g}, 1 \mathrm{mmol})$ and the phosphonium salt 8 (1.0 $\mathrm{g}, 1 \mathrm{mmol}$ ) in $15 \mathrm{~mL}$ of anhydrous ethanol and dry chlor oform (2:1). The mixture was stirred at room temperature overnight. The polymerization was quenched by adding $5 \mathrm{~mL}$ of dilute hydrochloric acid ( $2 \%$ in water) and stirring for a few minutes. The resultant material was dissolved in chloroform and filtered. The solution was concentrated in a vacuum and added dropwise to ethanol at room temperature with stirring to preci pitate the polymer. Reprecipitation was performed three times, and a bright yellow fibrous pol ymer was obtained after drying under vacuum at $40{ }^{\circ} \mathrm{C}(40 \%) .{ }^{1} \mathrm{H} \mathrm{NMR}\left(\mathrm{CDCl}_{3}, \delta\right): 7.5-$ $7.7(\mathrm{~m}, 16 \mathrm{H}), 7.0-7.3(\mathrm{~m}, 4 \mathrm{H}), 3.95(\mathrm{~m}, 4 \mathrm{H}), 1.6-2.1(\mathrm{~m}, 8 \mathrm{H})$, $1.3-1.5(\mathrm{~m}, 14 \mathrm{H}), 0.7-1.2(\mathrm{~m}, 26 \mathrm{H}) .{ }^{13} \mathrm{C} \mathrm{NMR}\left(\mathrm{CDCl}_{3}, \delta\right)$ : $149.41,132.19,131.14,131.01,130.93,130.89,129.39,128.80$, $128.26,127.55,127.39,125.03,119.68,115.07,68.65,39.50$, $30.58,30.46,28.74,28.33,24.76,22.71,21.59,13.01$. Elemental calcd for $\left(\mathrm{C}_{59} \mathrm{H}_{70} \mathrm{O}_{2}\right)_{n}$ : C, 87.36; $\mathrm{H}, 8.70$. Found: C, 86.30; $\mathrm{H}, 8.64$.

Poly[2 , 5'-dihexyloxy-p-terphenyl-4,4'-ylenevinylene2,5-thiophenediylvinylene] (B). This polymer was synthesized from $0.8 \mathrm{~g}(1 \mathrm{mmol})$ of phosphonium salt $\mathbf{1 0}$ and $0.49 \mathrm{~g}$ ( $1 \mathrm{mmol}$ ) of dialdehyde 5 to yield $0.3 \mathrm{~g}(65 \%)$ of an orange fibrous polymer. ${ }^{1} \mathrm{H}$ NMR $\left(\mathrm{CDCl}_{3}, \delta\right): 7.4-7.7(\mathrm{~m}, 8 \mathrm{H}), 7.1-$ $7.3(\mathrm{~d}, 4 \mathrm{H}), 6.9(\mathrm{~d}, 2 \mathrm{H}), 6.6(\mathrm{~d}, 2 \mathrm{H}), 3.95(\mathrm{~m}, 4 \mathrm{H}), 1.7(\mathrm{~m}, 4 \mathrm{H})$, $1.3(\mathrm{~m}, 12 \mathrm{H}), 0.9(\mathrm{~m}, 6 \mathrm{H}) .{ }^{13} \mathrm{C} N M R\left(\mathrm{CDCl}_{3}, \delta\right): 150.39,142.05$ 130.36, 129.86, 129.53, 128.30, 127.16, 125.95, 116.01, 69.59, 31.47, 29.34, 25.78, 22.58, 14.03. Elemental calcd for $\left(\mathrm{C}_{38} \mathrm{H}_{42} \mathrm{O}_{2} \mathrm{~S}\right)_{n}$ : C, 81.15; H, 7.47; S, 5.69. Found: C, 80.44; $\mathrm{H}$, 7.30; S, 4.81

\section{Results and Discussion}

The syntheses of the monomers and polymers are outlined in Scheme 1. 2,5-Bis(hexyloxy)-1,4-dibromobenzene (2) was used as a starting material for the synthesis of bis(hexyloxy-2,5-phenyldiboronic acid 1,3propanediol diester) (4). This was subsequently converted to hexyloxy-substituted terphenylene dialdehyde through a Pd-complex-catalyzed Suzuki coupling reaction. In a separate reaction, fluorene was reacted with 2.5 equiv of butyllithium in diethyl ether at $-78^{\circ} \mathrm{C}$. The resulting 9,9'-dilithiofluorene was reacted with 2.5 equiv of hexyl bromide at $-78^{\circ} \mathrm{C}$, yielding 9,9'-di-n-hexylfluorene (6). Phosphoni um salts $\mathbf{8}$ and $\mathbf{1 0}$ were synthesized from the reaction between triphenyl phosphine and 2,7bis(bromomethyl)-9,9'-di-n-hexylfluorene (7) and 2,5-bis(bromomethyl)-thiophene (9), respectively. The polymerization was carried out at room temperature in 2:1 (v:v) ethanol/chl or oform using sodium ethoxide as base and afforded polymers $\mathbf{A}$ and $\mathbf{B}$ as yellow and orange fibrous products. The ${ }^{1} \mathrm{H}$ NMR and ${ }^{13} \mathrm{C}$ NMR spectra of the polymers in chloroform-d and elemental analysis confirmed the expected polymer structures. The introduction of the dialkoxy side chains helped to prevent early precipitation during the polymerization process. The resonance for the aldehyde group was absent in the ${ }^{1} \mathrm{H}$ NMR spectra of both polymers, showing that no 
(a)
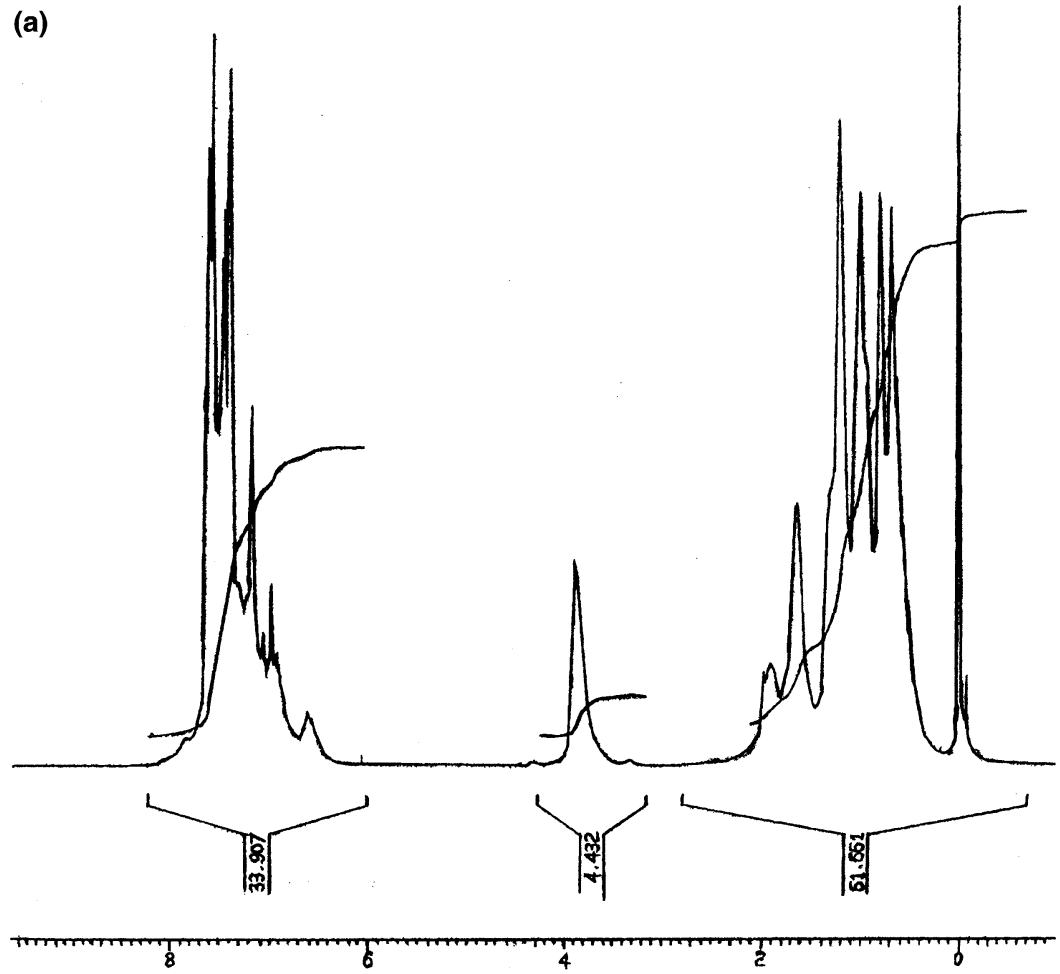

(b)

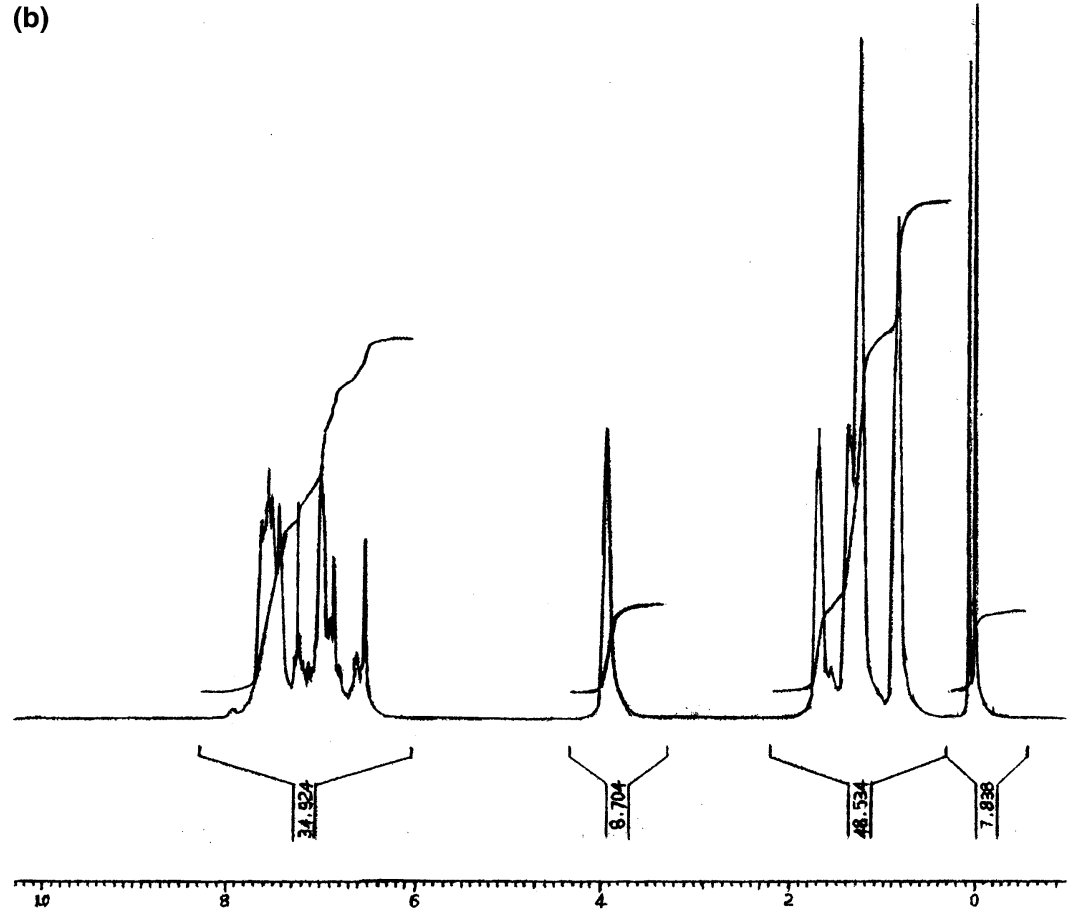

Figure 1. ${ }^{1 H}$ NMR spectra of polymer A (a) and polymer B (b).

monomeric residues remained in the polymers ( $F$ igure 1).

Both polymers were readily soluble in common organic solvents such as chloroform, methylene chloride, tetrahydrofuran, etc. Pinhole-free and homogeneous thin films could be formed by spin-coating from chloroform solutions. GPC analysis yielded weight-average molecular weights of polymer $\mathbf{A}$ and $\mathbf{B}$ of $1.3 \times 10^{4}$ and $2.4 \times 10^{4}$, respectively, with polydispersity indices of 2.8 and 3.2. Thermal stability of the polymers measured by thermogravimetric analysis (TGA) under a nitrogen atmosphere showed stabilities in the $400^{\circ} \mathrm{C}$ range. The weight loss of the polymers were less than $5 \%$ on heating to 390 and $410{ }^{\circ} \mathrm{C}$ for polymers A and B, respectively. However, polymer $\mathbf{B}$ had an initial weight loss (1\%) starting at $250{ }^{\circ} \mathrm{C}$ probably due to residual impurities. Glass transition temperatures $\left(T_{g}\right)$ of 67 and $78{ }^{\circ} \mathrm{C}$ (second heat) for $\mathbf{A}$ and $\mathbf{B}$ were determined by differential scanning calorimetry (DSC) analysis in a nitrogen atmosphere at a heating rate of $20^{\circ} \mathrm{C} / \mathrm{min}$.

The absorption and emission spectra of polymer $\mathbf{A}$ and B in chloroform $\left(10^{-5} \mathrm{M}\right)$ solution and in solid film are shown in Figures 2 and 3, and the respective maxima and fluorescence quantum yields are listed in Table 1. The UV spectrum of a dilute solution and a film of $\mathbf{A}$ showed $\lambda_{\max }$ at 395 and $400 \mathrm{~nm}$, respectively, with a 
Table 1. Optical Properties of Polymers in Chloroform (10-5 $\mathrm{M})$ and in Films

\begin{tabular}{|c|c|c|c|c|c|c|c|}
\hline \multirow[b]{2}{*}{ polymer } & \multicolumn{2}{|c|}{$\lambda_{\max }(\mathrm{nm})$ absorption } & \multicolumn{2}{|c|}{$\lambda_{\max }(\mathrm{nm})^{\mathrm{a}}$ emission } & \multirow[b]{2}{*}{$\varphi \mathrm{f}^{\mathrm{b}}$} & \multirow{2}{*}{$\begin{array}{l}\text { Stokes shift } \\
\text { (film) }(\mathrm{nm})\end{array}$} & \multirow[b]{2}{*}{$\mathrm{EL}(\mathrm{nm})$} \\
\hline & solution & film & solution & film & & & \\
\hline $\begin{array}{l}\text { A } \\
\text { B }\end{array}$ & $\begin{array}{l}\text { 395, (420) } \\
406,(455)\end{array}$ & $\begin{array}{l}400,(428) \\
406,(462)\end{array}$ & $\begin{array}{l}445,(465,505) \\
478,(515)\end{array}$ & $\begin{array}{l}469 \\
538,(570)\end{array}$ & $\begin{array}{l}0.79 \\
0.13\end{array}$ & $\begin{array}{r}69 \\
132\end{array}$ & $\begin{array}{l}515 \\
579\end{array}$ \\
\hline
\end{tabular}

a Excited at $360 \mathrm{~nm}$. b 9,10-Diphenylanthracene used as standard. c Numbers in parentheses indicate spectral shoulders.

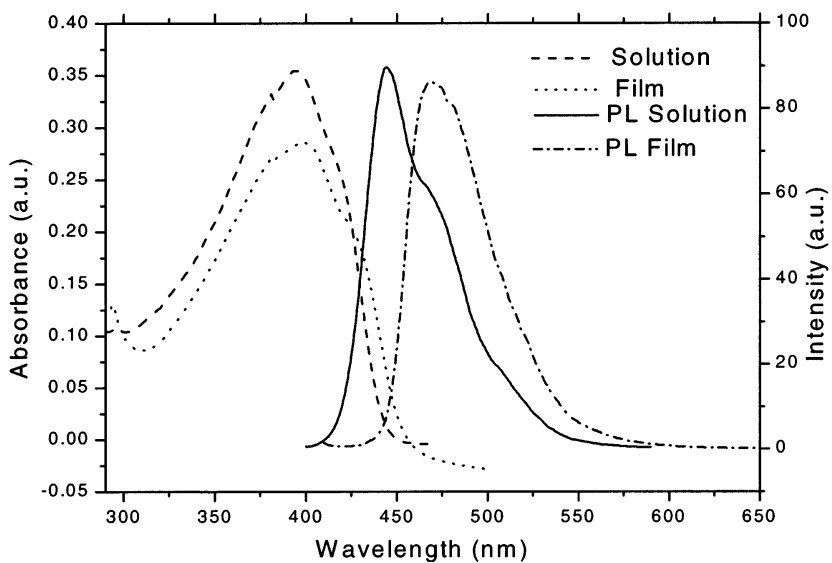

Figure 2. Absorption and emission spectra of $\mathbf{A}$ in chloroform $\left(10^{-5} \mathrm{M}\right)$ and in the solid state at room temperature.

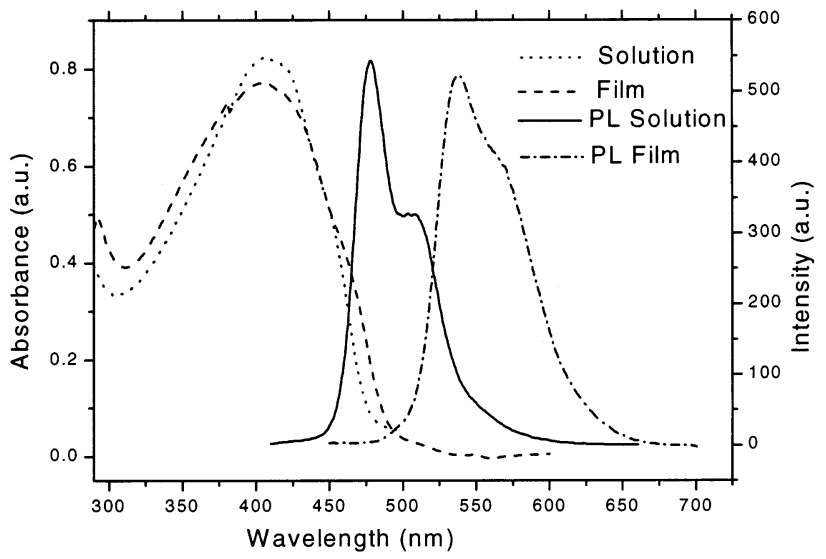

Figure 3. Absorption and emission spectra of $\mathbf{B}$ in chloroform $\left(10^{-5} \mathrm{M}\right)$ and in the solid state at room temperature.

small bathochromic shift in the film. The maximum emission in the photoluminescence spectrum of the solution was observed at $445 \mathrm{~nm}$ with shoulders at 465 and $505 \mathrm{~nm}$, resulting from a vibronic-excitonic interaction attributed to the coupling of the phenylene ring stretching modes of the main chain to the el ectronic $\pi$, $\pi^{*}$ transitions. ${ }^{31}$ The PL spectrum of the film was centered at $469 \mathrm{~nm}$, corresponding to a blue emission. The red shift relative to the solution is attributed to packing effects in the local geometry of the polymers. ${ }^{32}$

The main emission peak of polymer $\mathbf{A}$ is significantly red-shifted with respect to the polymer poly(9,9-dihexylfluorene-alt-1,4-phenylene) (PDHFP) (Scheme 3) which exhibits PL maxima in the solution and the film at 410 and $420 \mathrm{~nm}$, respectively. $19,27,33$ The vinylene unit in $\mathbf{A}$ apparently develops a high degree of coplanarity with the fluorene unit in the copolymer backbone. In contrast, the main emission peak of $\mathbf{A}$ is blue-shifted with respect to poly(9,9-di-hexylfluorenediylvinylene-alt1,4-phenylenevinylene) (PDHFPPV) (Scheme 3) which shows PL maxima for the solution and the film at 477 and $482 \mathrm{~nm}$, respectively, ${ }^{34}$ indicating that the effective conjugation of polymer $\mathbf{A}$ is partially interrupted, resulting in 9,9-dihexylfluorenediylvinylene-1,4-phen-
Scheme 3. Chemical Structures of Polymers A, PDHFP, and PDHFPPV
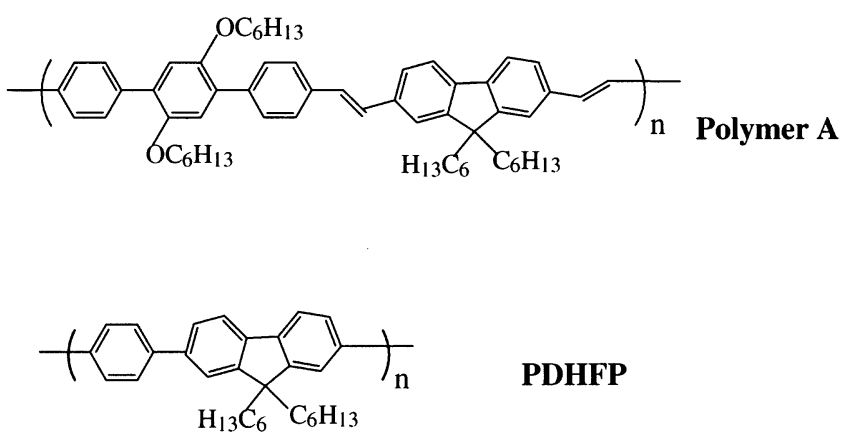

PDHFP

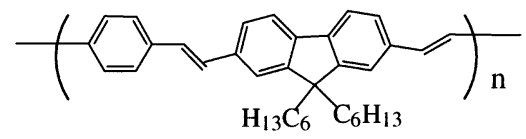

PDHFPPV

ylene chromophores connected to each other by noncoplanar phenylene groups. It has been suggested that isolated unsubstituted ol igophenylenes are nonplanar, presumably due to ortho-hydrogen interactions. ${ }^{35-37}$ Substitution with hexyloxy groups in the middle phenyl ring results in a larger torsional angle between the two consecutive aryl units because of the increased steric interactions.

Figure 3 shows the absorption and PL spectra of polymer $\mathbf{B}$ in chloroform $\left(10^{-5} \mathrm{M}\right)$ solution and in the solid film. A maximum absorption peak both in dilute solution and in the solid state is seen at $406 \mathrm{~nm}$, attributed to a $\pi-\pi^{*}$ transition. The PL spectra showed an emission maximum at $478 \mathrm{~nm}$ with a shoulder at $515 \mathrm{~nm}$ in the solution and at $538 \mathrm{~nm}$ with a shoulder at $570 \mathrm{~nm}$ in the thin film when excited at $400 \mathrm{~nm}$. In general, the presence of vibronic structures in an emission spectrum indicates that the polymer has a rigid and well-defined backbone structure. 38,39 The emission spectrum of polymer $\mathbf{B}$ is significantly redshifted with respect to $\mathbf{A}$, corresponding to a larger Stokes shift. The peak difference between the absorption and emission spectra of $\mathbf{B}$ was substantial (132 nm), almost twice that of $\mathbf{A}$. This results from the inherent electron-rich nature of the thiophene moiety. The relative fluorescence quantum yields of the polymers were determined in dilute chloroform solution using 9,10diphenylanthracene in cyclohexane as standard. As expected, polymer A has a somewhat enhanced fluorescence quantum yield because of the presence of the fluorene unit. As already noted, fluorene derivatives have extremely high luminescence efficiencies in solution, rivaling those of many laser dyes ${ }^{6-8}$ The quantum yield of $\mathbf{B}$ in chloroform $\left(10^{-5} \mathrm{M}\right)$ is significantly lower than that of A. Studies of PL processes in oligo- and polythiophenes attribute the low PL efficiency to an intersystem crossing of excitons to triplet states. 30,40 


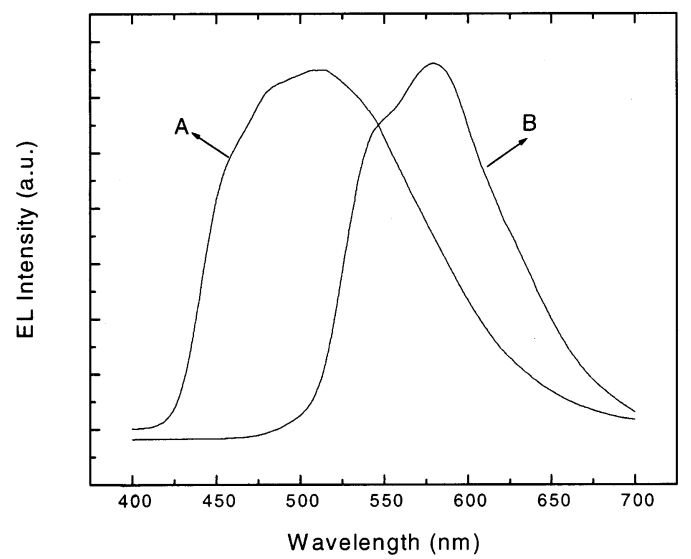

Figure 4. Electroluminescence spectra of ITO/PEDOT/polymer/ Ca/Al LEDs using $\mathbf{A}$ and $\mathbf{B}$.

Double-layer LEDs with structures ITO/PEDOT/ polymer/Ca/Al utilizing polymers A and B ("devices A and $\mathbf{B}$ ") as emissive layer were fabricated. Devices A and $\mathbf{B}$ emit green and yellow light at 515 and $579 \mathrm{~nm}$, respectively (Figure 4 ). In the EL spectrum of device B, there is a shoulder at $549 \mathrm{~nm}$, corresponding to the $0-0$ transition. Comparing the EL and PL spectra of polymer $\mathbf{B}$, we see a relative intensity change in the two $0-0$ and $0-1$ vibronic peaks. The $0-1$ peak in the $E L$ spectrum is strongly enhanced, indicating that excitons in the LED prefer the lower energy states. The EL of polymer A shows a large red shift of about $46 \mathrm{~nm}$ compared to the PL and a significant spectral broadening. The red shift in the EL spectrum is attributed to the fact that el ectroluminescent excitons are generally adequately thermal ized compared to photoluminescent excitons as a result of their different modes of generation. The tailing in the long wavel ength region is largely due to defects in the emissive polymer layer which act as new recombination centers in which excitons radiatively decay giving emissions different from those given by excitons decaying on the pristine polymer main chain. ${ }^{41-43}$ The obvious spectral broadening of the $E L$ spectrum of polymer $\mathbf{A}$ compared to $\mathbf{B}$ is attributed to the formation of interchain emitting states ${ }^{44}$ and, in part, from a less ordered solid-state structure. The current-voltage-luminance relationship for the two LEDs is shown in Figure 5. The turn-on voltages for the emission for devices $\mathbf{A}$ and $\mathbf{B}$ are 6 and $10 \mathrm{~V}$, respectively. For device $\mathbf{B}$, the turn-on voltages for light and current differ, indicating an imbalance of hole and electron injection, whereas device A shows a near perfect carrier injection balance. This cannot be accounted for quantitatively but qualitatively must involve a contribution from the fluorene units present.

It has been found that layered silicates dispersed in a polymer matrix yield advantages in light-emitting systems. ${ }^{22,45}$ In the present study, to confirm the intercalation of polymer A into C15A after the procedure noted above, a small-angle X-ray scattering (SAXS) study was carried out. Figure 6 shows the XRD profiles of C15A before and after the polymer intercalation. The pure silicate shows a single peak at $2 \theta=2.80^{\circ}$. In all the intercalated samples the location of this peak has changed to $2 \theta=2.39^{\circ}$. This indicates that the interlayer $\mathrm{d}_{001}$ spacings are expanded from $3.15 \mathrm{~nm}$ in pure C15A to $3.69 \mathrm{~nm}$ in a polymer A/C15A composite film. The optical microscopy of the $110 \mathrm{~nm}$ thick films showed homogeneity on the micron scale. However, AFM images of the same films containing $50 \%$ or $9 \% \mathrm{w} / \mathrm{w}$ clay (F igure
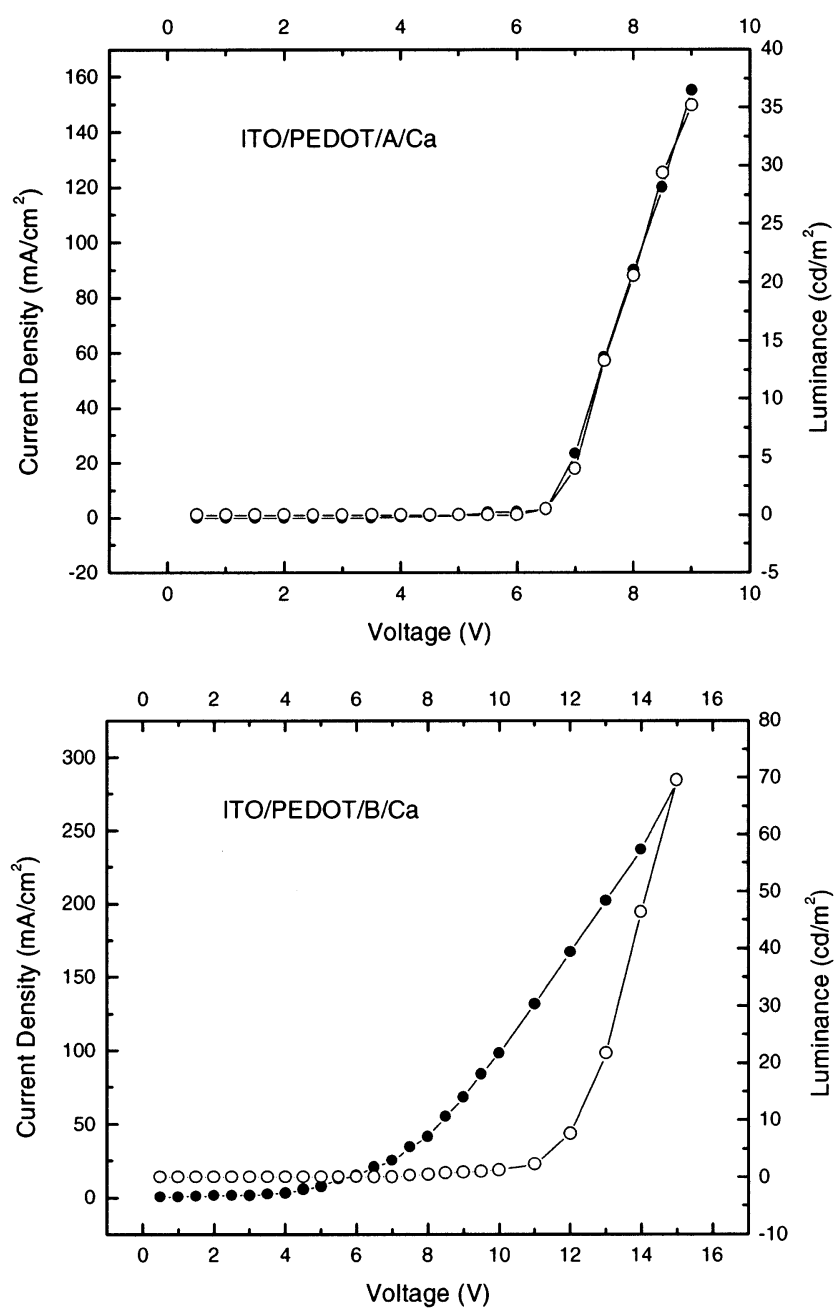

Figure 5. Current density $(\bullet)$ and luminance $(O)$ as a function of voltage for ITO/PEDOT/A/Ca/AI and ITO/PEDOT/B/Ca/AI LEDs.

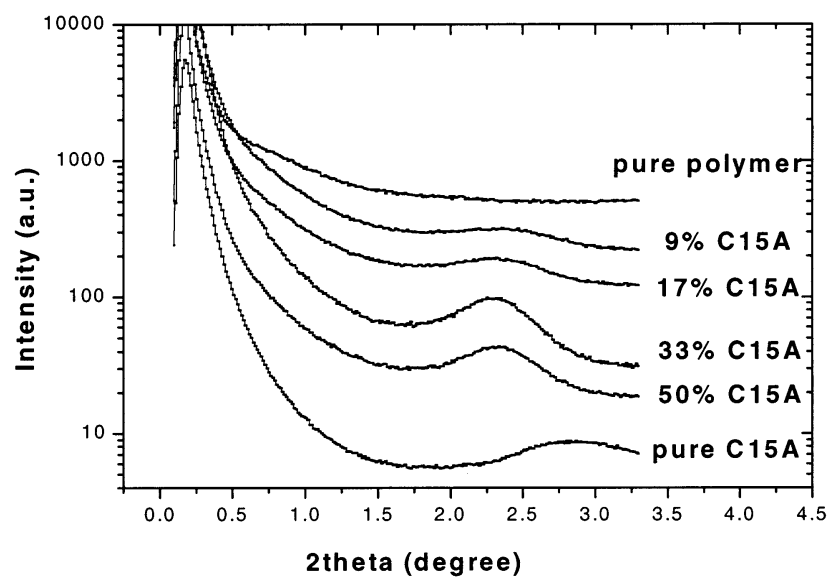

Figure 6. SAXS curves of C15A intercalated with polymer A. Different contents of C15A are shown.

7) showed the presence of some approximately $100 \mathrm{~nm}$ aggregates of clay protruding from the surfaces of the films. The remaining nonaggregated inorganic material is covered by polymer.

PL spectra of the composite films of the same thickness are shown in Figure 8. The emitted light emanates from both the neat and the intercalated polymers. There is no change in the PL emission maximum with intercalation in this system, in contrast to what was observed in refs 22 and 45 . The difference is due to the fact that 


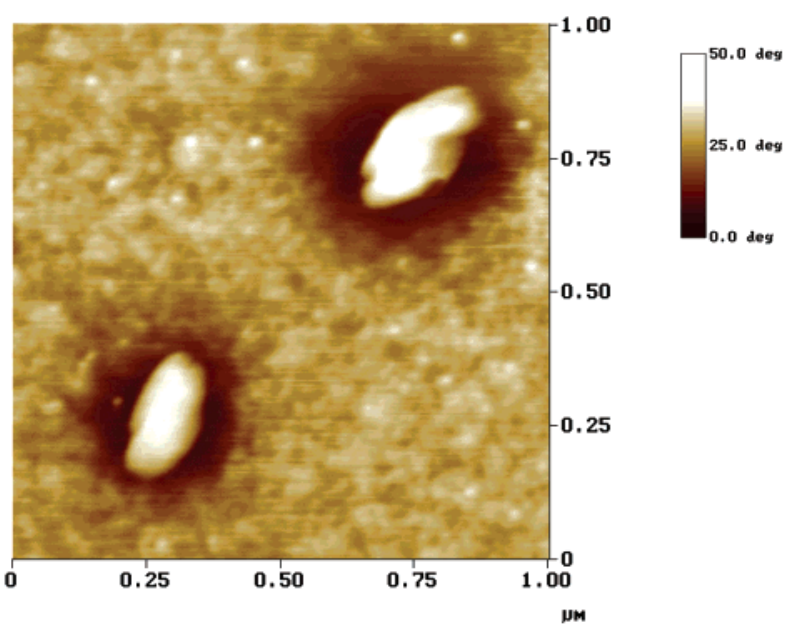

(a) $\mathrm{C} 15 \mathrm{~A}$ content: $50 \%$ by weight

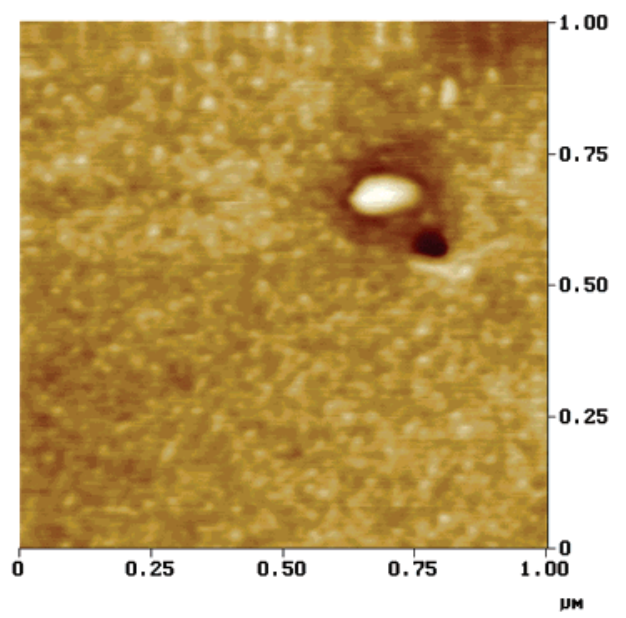

(b) C15A content: $9 \%$ by weight

Figure 7. AFM phase contrast images of nanocomposites thin films with a C15A content of (a) $50 \%$ and (b) $9 \%$. I mage sizes are $1 \mu \mathrm{m} \times 1 \mu \mathrm{m}$.

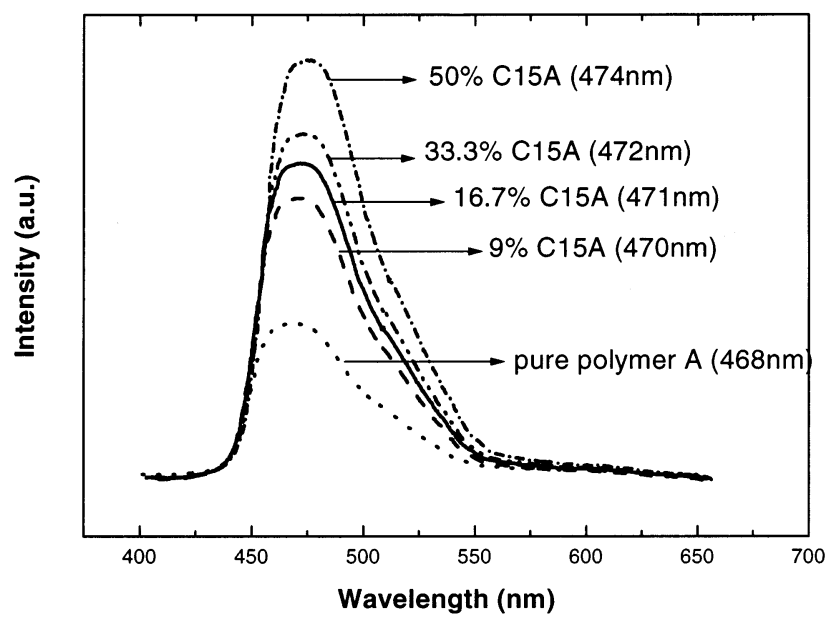

Figure 8. Photoluminescence spectra of the $\mathbf{A} / \mathrm{C} 15 \mathrm{~A}$ films.

in the earlier study a fully conjugated system was intercalated, in contrast to the partially conjugated polymer $\mathbf{A}$ in the present case. This affects the change in effective conjugation length associated with the conformational changes brought about by the intercalation. Polymer $\mathbf{A}$ is isolated within the 2-dimensional lamellar structure; consequently, a decrease of inter-

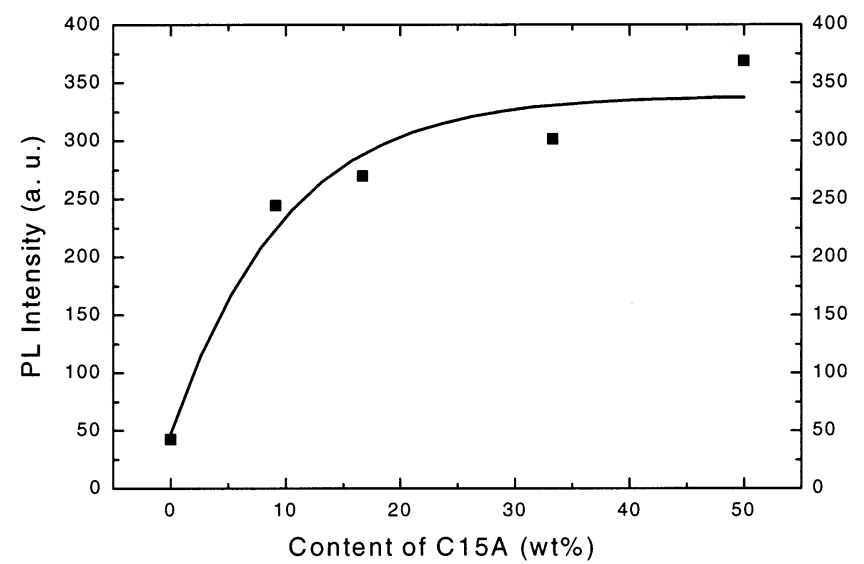

Figure 9. Maximum $P L$ intensities of $\mathbf{A} / C 15 A$ composite films as a function of C15A content.

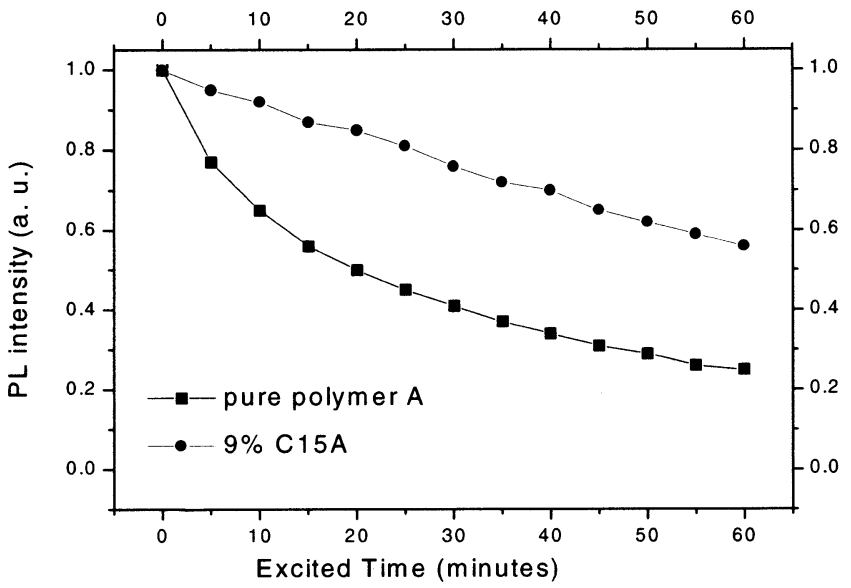

Figure 10. Degradation of PL intensity as a function of the irradiation time in air; see text.

chain interaction can be expected, which strongly affects PL efficiency. ${ }^{46-50}$ Thus, intercalation produces significant enhancement of photol uminescence of these films (Figure 9). For the sample with the highest concentrati on of C15A the PL intensity was 10 times higher than that of the film of pure polymer $\mathbf{A}$ of the same thickness excited at the same wavelength. Intercalation also reduced the degradation of $\mathrm{PL}$ intensity with time of the irradiated films (Figure 10), which was carried out with monochromatic $400 \mathrm{~nm}$ light from a xenon lamp in air. Both the photooxidation and photodegradation processes were retarded in the composite films in which the silicate reduced oxygen and moisture penetration into the emissive layer. ${ }^{22,48} \mathrm{~F}$ urther study of the electroluminescence properties of these composites is in progress.

\section{Conclusions}

Two light-emitting polymers $\mathbf{A}$ and $\mathbf{B}$ composed of regularly alternating terphenylene linked by fluorenediylvinylene and thiophenediylvinylene units have been prepared by Wittig polycondensation. Both $\mathbf{A}$ and $\mathbf{B}$ display good thermal stability and solubility in common organic solvents. Control of $\pi$-conjugation in the polymers was achieved through steric interaction induced by the side chains in the terphenyl blocks and through the presence of the vinylene blocks. Composites were prepared from polymer $\mathbf{A}$ and an organo-clay, in which A molecules were intercalated. The PL efficiency and photodegradation resistance improved after intercalation. 
Acknowledgment. This work was supported by the Air F orce Office of Scientific Research (Grant F 4962099-1-002).

\section{References and Notes}

(1) Yang, Y.; Heeger, A. J . Nature (London) 1994, 372, 344

(2) Strukelj, M.; Papadimitrakopoulos, F.; Miller, T. M.; Rothberg, L. J . Science 1995, 270, 1969.

(3) Andersson, M.; Yu, G.; Heeger, A. J . Synth. Met. 1997, 85, 1275.

(4) Kim, D. Y.; Cho, H. N.; Kim, C. Y. Prog. Polym. Sci. 2000 25,1089

(5) Dai, L.; Winkler, B.; Dong, L.; Tong, L.; Mau, A. W. H. Adv. Mater. 2001, 13, 915.

(6) Pei, Q.: Yang, Y. J . Am. Chem. Soc. 1996, 118, 7416.

(7) Yang, Y.; Pei, Q. J . Appl. Phys. 1997, 81, 3294.

(8) Klaerner, G.; Miller, R. D. Macromolecules 1998, 31, 2007.

(9) J anietz, S.; Bradley, D. D. C.; Grell, M.; Giebeler, C.; Inbasekaran, M.; Woo, E. P. Appl. Phys. Lett. 1998, 73, 2453.

(10) Kim, J. S.; Friend, R. H.; Cacialli, F. Appl. Phys. Lett. 1999, 74,3084

(11) Roncali, J . Chem. Rev. 1992, 92, 71.

(12) Braun, D.; Gustafsson, G.; McBranch, D.; Heeger, A. J . J . Appl. Phys. 1992, 72, 564.

(13) Chen, F.; Metha, P. G.; Takiff, L.; McCullough, R. D. J . Mater. Chem. 1996, 6, 1763.

(14) Andersson, M. R.; Berggren, M.; Inganäs, O.; Gustafsson, G.; Gustafsson-Carlberg, J . C.; Selse, D.; Hjertberg, T.; Wennerström, O. Macromolecules 1995, 28, 7525.

(15) Chen, S.-A.; Tsai, C.-C. Macromol ecules 1993, 26, 2234

(16) Pei, Q.; Zuccarello, G.; Ahlskog, M.; Inganäs, O. Polymer 1994 35, 1374.

(17) Kreyenschmidt, M.; Klaerner, G.; Fuhrer, T.; Ashenhurst, J .; Karg, S.; Chen, W. D.; Lee, V. Y.; Scott, J . C.; Miller, R. D. Macromolecules 1998, 31, 1099.

(18) Klaerner, G.; Davey, M. H.; Chen, W. D.; Scott, J . C.; Miller, R. D. Adv. Mater. 1998, 10, 993.

(19) Liu, B.; Yu, W. L.; Lai, Y.-H.; Huang, W. Chem. Mater. 2001, 13, 1984.

(20) Okada, A.; Usuki, A. Mater. Sci. Eng. C 1995, 3, 109.

(21) Yano, K.; Usuki, A.; Okada, A.; Kurauchi, T.; Kamigito, O J . Polym. Sci., Part A: Polym. Chem. 1993, 31, 2493.

(22) Lee, T. W.; Park, O. O.; Kim, J .-J .; Hong, J .-M.; Kim, Y. C. Chem. Mater. 2001, 13, 2217.

(23) Huber, J .; Scherf, U. Macromol. Rapid Commun. 1994, 15, 897.

(24) Tong, T.-H.; Chien, L.-C. J . Polym. Sci., Part A: Polym. Chem 2000, 38, 1450 .
(25) Demas, J . N.; Crosby, G. A. J . Phys. Chem. 1971, 75, 991.

(26) Hamai, S.; Hirayama, F. J . Phys. Chem. 1983, 87, 83.

(27) Hu, B.; Karasz, F. E. Chem. Phys. 1998, 227, 263.

(28) Ranger, M.; Rondeau, D.; Leclerc, M. Macromolecules 1997 30, 7686.

(29) Liu, B.; Yu, W. L.; Pei, J .; Liu, S. Y.; Lai, Y. H.; Huang, W. Macromol ecules 2001, 34, 7932.

(30) Inganäs, O.; Granlund, T.; Theander, M.; Berggren, M.; Andersson, M. R.; Ruseckas, A.; Sundström, V. Opt. Mater. 1998, 9, 104.

(31) Fujii, T.; Suzuki, S.; Komatsu, S. Bull. Chem. Soc. J pn. 1982 $55,2576$.

(32) Kim, Y.; Kwon, S.; Yoo, D.; Rubner, M. F.; Wrighton, M. S. Chem. Mater. 1997, 9, 2699.

(33) Cho, H. N.; Kim, D. Y.; Kim, J . K.; Kim, C. Y. Synth. Met. 1997, 91, 293.

(34) Cho, H. N.; Kim, D. Y.; Kim, Y. C.; Lee, J. Y.; Kim, C. Y. Adv. Mater. 1997, 9, 326.

(35) Tour, J. M. Adv. Mater. 1994, 6, 190

(36) Hilberer, A.; van Hutten, P. F.; Wildeman, J .; Hadziioannou, G. Macromol. Chem. Phys. 1997, 198, 2211.

(37) Baker, K. N.; Fratini, A. V.; Resch, T.; Knachel, H. C.; Adams, W. W.; Socci, E. P.; Farmer, B. L. Polymer 1993, 34, 1571

(38) Braun, D.; Heeger, A. J . Appl. Phys. Lett. 1991, 58, 1982.

(39) Cimrova, V.; Remmers, M.; Neher, D.; Wegner, G. Adv. Mater. 1996, 8, 146.

(40) Beljonne, D.; Cornil, J .; Friend, R. H.; J anssen, R. A. J .; Bredas, J . L. J . Am. Chem. Soc. 1996, 118, 6453.

(41) Ng, S.; Lu, H.; Chan, H. S. O.; Fujii, A.; Laga, T.; Yoshino, K. Adv. Mater. 2000, 12, 1122

(42) Tao, X.; Zhang, Y.; Wada, T.; Sasabe, H.; Suzuki, H.; Watanabe, T.; Miyata, S. Adv. Mater. 1998, 10, 226.

(43) Cimrová, V.; Neher, D.; Remmers, M.; Kmínek, I. Adv. Mater. 1998, 10, 676 .

(44) Theander, M.; J ohansson, D. M.; Ruseckas, A.; Zigmantas, D.; Andersson, M. R.; Sundström, V.; Inganäs, O. Synth. Met. 2001, 119, 615

(45) Winkler, B.; Dai, L.; Mau, A. W.-H. J . Mater. Sci., Lett. 1999, $18,1539$.

(46) J enekhe, S. A.; Osaheni, J . A. Science 1994, 265, 765.

(47) Nguyen, T.-Q.; Martini, I. B.; Liu, J .; Schwartz, B. J . J . Phys. Chem. B 2000, 104, 237.

(48) Yan, M.; Rothberg, L. J .; Papadimitrakopoulos, F.; Galvin, M. E.; Miller, T. M. Phys. Rev. Lett. 1994, 73, 744.

(49) Yan, M.; Rothberg, L. J .; Kwock, E. W.; Miller, T. M. Phys. Rev. Lett. 1995, 75, 1992

(50) J akubiak, R.; Rothberg, L. J .; Wan, W.; Hsieh, B. R. Synth. Met. 1999, 101, 230.

MA020533N 